International Journal of Health Sciences
Available online at www.sciencescholar.us
Vol. 5 No. 3, December 2021, pages: 449-460
e-ISSN: 2550-696X, p-ISSN: 2550-6978
https://doi.org/10.53730/ijhs.v5n3.1905

\title{
Promoting Healthy Births and Reducing Infant Mortality Through National Health System
}

\author{
Malachynska Mariya ${ }^{a}$, Petro Kuzyk ${ }^{b}$, Oleg Diegtiar ${ }^{c}$
}

Manuscript submitted: 27 June 2021, Manuscript revised: 18 August 2021, Accepted for publication: 09 October 2021

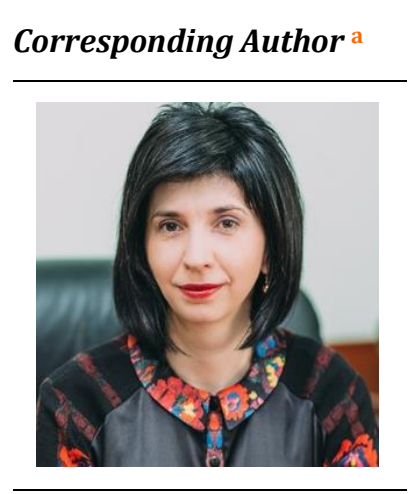

\section{Keywords}

beveridge model; health care system; healthy births; infant mortality; maternal mortality ratio; perinatal medical care; women health care;

\begin{abstract}
The main value of both the national economy and the global community is the human being. Therefore, the strategy of sustainable development is focused on the primary factors that ensure human development and the realization of man's divine inalienable right to a full life. The central link in the realization of this right is the organization of the system of medical care, primarily for mothers and children. Perinatal care determines the level of socio-economic development of the country in the global environment and is determined by the perspective of the modern international economy in terms of acceptability of generations, determines the level of competitiveness of national production and its final consumption. The conducted research characterized the goals and objectives of the WHO to implement the strategy of sustainable development, namely that every woman, every child, and adolescent anywhere in the world could realize the right to health. This goal national governments must achieve by the end of 2050. Therefore, from the perspective of this concept, an assessment of perinatal health care was carried out.
\end{abstract}

International Journal of Health Sciences (C) 2021. This is an open access article under the CC BY-NC-ND license (https://creativecommons.org/licenses/by-nc-nd/4.0/).

\section{Contents}

Abstract 449

1 Introduction 450

2 Materials and Methods 450

3 Results and Discussions 451

4

Acknowledgments..

References 457

Biography of Authors 458 460

a Danylo Halytsky Lviv National Medical University, Lviv, Ukraine

${ }^{\text {b }}$ Bogomolets National Medical University, Kyiv, Ukraine

c Vasyl Stefanyk Precarpathian National University, Ivano-Frankivsk, Ukraine 


\section{Introduction}

In the global population growth tendency of the planet at the regional level, there is outstripping aging of the population, primarily in developed countries. It is a serious demographic problem for national economies, which is mainly solved by attracting the flow of immigrants. However, the population reproduction policy is the most important component of the state demographic policy because its basis is formed by fertility and overcoming child mortality. Therefore, the World Health Organization (WHO) defines the problem of infant and maternal mortality as the main problem of the 21st century.

The child and maternal mortality ratio are determined by a significant range of socio-economic factors of the country (Hill et al., 2007). However, maternal and child health care measures make it possible to significantly change the negative overall tendency, even in underdeveloped countries. One of the WHO decisions notes the necessity for the governments of the countries to provide the conditions of availability of palliative care and to bring it to the rank of moral responsibility of the national health care system, which serves as a leading factor in the achievement of the Global Sustainable Development Goals. This research aims to analyze the assessment of perinatal care state regulation based on the national and international statistical data in achieving sustainable development.

Research tasks

- To analyze mechanisms and measures of governmental action to increase healthy birth and survival of children under the age of five.

- To analyze groups of the world's countries according to the criterion of economic development level of infant mortality and identify common and specific patterns in the system of national health care and thereby indicate the contribution of these countries to the achievement of sustainable development of the world' community.

- To assess the level of perinatal medicine development due to market criteria in the developed countries of the world.

The state management of prenatal care is impossible in conditions of extreme poverty and lack of employment in the country.

\section{Hypothesis}

It should be expected that the implementation of the concept of sustainable development of countries will lead to the fact that the level of perinatal care negative indicators will be reduced due to state regulation of this sphere.

\section{Materials and Methods}

Both qualitative and quantitative studies analyzing the Sustainable Development Goals exist in the academic literature (Resolution A/RES/70/1, 2015). However, the majority of scholars (Buse \& Hawkes, 2015; Dye \& Acharya, 2017; Rasanathan \& Diaz, 2016; Maher \& Cometto, 2016; Valentine \& Bonsel, 2016; Wong et al., 2016; Ruckert et al., 2017; Scott et al., 2018), agree that health is central to the UN Sustainable Development Goals. Almost all of the other 16 goals are health-related. The goal of the Sustainable Development Goals is to promote the global well-being of women, newborns, families, communities, the nation, and the global community as a whole (Requejo \& Bhutta, 2015). In recent years, significant efforts have been made to reduce illness and mortality by focusing on specific subpopulations (e.g., "poor," "women and children") (Buse \& Hawkes, 2015). Some scholars (Callister \& Corbett, 2017; Boerma et al., 2018; Kruk et al., 2018; Lawn et al., 2016; Bhutta et al., 2014), in the context of sustainability research, focus on the role of perinatal care. 
Thus, Kikuchi et al. (2016), evaluate the effectiveness of linking prenatal care and pregnancy care in reducing neonatal, perinatal, and maternal mortality in low- and middle-income countries. Watson et al., (2019), investigated the ability of ethnic minority women to receive adequate perinatal support in the UK. Whipps et al. (2021), argues that in the 21st century, access to health care is a critical indicator of the wellbeing of any country's population.

Despite a rather wide range of state regulation researches in the sphere of perinatal care, the question of state regulation efficiency is in the debate (Layuk et al., 2021; Widana et al., 2021). For developed countries, it is irrelevant research, and for less developed countries, it is an urgent challenge to implement schemes and mechanisms of government policy in the health care system. Therefore, the research will reveal the state regulation efficiency level of maternal and child health by groups of world countries. The realization of research aim implies the use of the following methods:

- Systematization, generalization of scientific publications on the study and evaluation of state perinatal care, in particular, the introduction and distribution of special perinatal centers and their further cooperation with various international funds and projects to populate and disseminate this experience in underdeveloped countries were considered.

- The method of comparative analysis by selected indicators of child mortality. This method is the leading in calculating the rating of countries according to the level of state aid, which allowed to determine the leading and outsider countries.

- The methods of elementary mathematics, taking into account macroeconomic indicators to assess the level of national perinatal care. The study used GDP per capita and health care expenditures per capita to determine the proportion of a country's expenditures per newborn death. This is the state's effort to survive newborns.

Systemic and logical analysis, the method of synthesis of information. Through these methods, analytical comparisons were made, and the indicators and conclusions of previous studies on this topic were coordinated.

\section{Results and Discussions}

In 2015, WHO adopted the Global Health Strategy for Women, Children and Adolescents 2016-2030 (WHO, 2015), which puts forward the goal that by 2030, every woman, child, and teenager anywhere in the world must be ensured the conditions for exercising the right to health. It means that governments and parliaments around the world must make the health of women, children, and adolescents their strategic priority. In economic terms, government efforts for the health of children and adolescents are highly economically feasible. Such measures during 1965-1990 in Asian developing countries (South Korea, Singapore, Hong Kong, Taiwan) ensured their economic growth of $30-50 \%$. These indicators were achieved solely by reducing the infant mortality rate because of measures that increased fertility ratios and reproductive health indicators. In addition, the conclusions of the 1990-2013 study noted that 50\% of the world's child deaths are concentrated in 6 countries (India, Pakistan, Congo, Democratic Republic of Congo, Nigeria, Ethiopia). At the same time, these countries are characterized by a very low standard of living (Kyu et al., 2016). Recent studies have identified general tendencies (WHO, 2015) that reveal the following persistent and dominant problems, not only of a purely organizational and medical nature.

Group I concerning teenage girls:

- The mortality rate of this group at the age of 15-19 years is high and is caused by suicide and complications of their health during pregnancy and childbirth.

- 120 million girls under the age of 20 are sexually abused, which is 1 out of 10 teenage girls.

- Failed female genital surgeries. According to forecasts in the nearest 10 years, the number of such victims can reach 30 million people.

Mariya, M., Kuzyk, P., \& Diegtiar, O. (2021). Promoting healthy births and reducing infant mortality through national health system. International Journal of Health Sciences, 5(3), 449-460. https://doi.org/10.53730/ijhs.v5n3.1905 
Group II - general sanitary and epidemiological problems:

- One-third (32\%) of the world's population lacks access to clean drinking water.

- $9 \%$ of the world's population lacks access to minimally necessary sanitation.

- Lack of water supply in $40 \%$ of health facilities in 59 countries. In $30 \%$ of countries, there is even a lack of simple soap for handwashing.

- Lack of toilets in $20 \%$ of medical institutions.

Group III - disadvantageous socio-economic environment of underdeveloped countries:

- The number of teenage pregnancies among indigenous girls in rural areas is up to 3 times higher than in urban areas.

- Difference up to $80 \%$ in the proportion of births attended by skilled health workers between the richest and poorest populations in individual countries.

- Up to $25 \%$ gap in prenatal care coverage (at least for four visits) between the most and the least educated and between the richest and the poorest population groups in selected countries.

- A gap of at least $18 \%$ in rates of care-seeking for symptoms of childhood pneumonia between the richest and poorest populations in individual countries, with overall low rates of care-seeking.

- The prevalence of growth retardation in children and mothers with no education is higher by up to $39 \%$ compared with children whose mothers attended high school or received higher education.

Overall, such researches have established quite logical things. Worse health outcomes are observed among women, children, and adolescents who are marginalized or excluded by society, suffer discrimination, and are under-served, especially among those who live in remote areas in poverty and lack at least a basic education (Barnett et al., 2012; Hardianti et al., 2021). Therefore, a strong correlation has been formed between the mortality ratio of children under 5 years of age and the financial and educational status of the child's mother in society (Table 1).

Table 1

The mortality ratio of children under the age of 5 depending on the financial and educational status of the mother

\begin{tabular}{lll}
\hline Factor group & Level & Mortality per 1000 liveborn \\
\hline Financial status & The poorest & 95 \\
& Low-income & 91 \\
& Middle class & 79 \\
& Wealthy & 68 \\
Mother's education & Rich & 48 \\
& Have no education & 110 \\
& Elementary education & 92 \\
Source: author's elaboration based on European Health Information Gate (2021)
\end{tabular}

According to the United Nations' international assessment and WHO information, the risk of maternal and child mortality is forecasted for the continental section (Table 2). The most dangerous regions are marked accordingly. These are usually Africa, Latin America, and the Caribbean. 
Table 2

The risk of newborn and teenage mortality

\begin{tabular}{lll}
\hline \multirow{2}{*}{ Region } & \multicolumn{1}{c}{ Age risk group } \\
\cline { 2 - 3 } & $\begin{array}{l}\text { Children under 5 } \\
\text { years old }\end{array}$ & $\begin{array}{l}\text { Girls under 15 years old } \\
\text { (death due to maternal pathologies) }\end{array}$ \\
\hline North America & $1: 143$ & $1: 4500$ \\
Latin America and the Caribbean & $1: 56$ & $1: 180$ \\
Eastern Mediterranean & $1: 18$ & $1: 520$ \\
Africa & $1: 11$ & $1: 40$ \\
Europe & $1: 83$ & $1: 3300$ \\
Southeast Asia & $1: 21$ & $1: 210$ \\
Western Pacific & $1: 67$ & $1: 1200$ \\
\hline Source: author's elaboration based on World Health Organization (2021), European Health Information Gate (2021)
\end{tabular}

The World Bank noted that in 1990 more than a third of the world's population lived on less than $\$ 1.9$ a day. In 30 years, more than one billion people have been able to lift themselves out of poverty, and about half of the world's countries have reduced the proportion of poor people to less than $3 \%$ (The World Bank, 2021). But such changes have not significantly improved mortality in children and adolescents.

Globally, the health of children and adolescents worldwide has improved dramatically over the past 20 years. However, such changes have not been uniform. Significant impact on reducing child mortality over the past decade has been achieved in countries in the European region (Kyu et al., 2018), and the United States (Data Bank, 2017).

In addition, in countries (territories) with a low socio-demographic index, the opposite situation is observed - an increase in the mortality rate of children and adolescents. In particular, this situation is typical for East Africa and Oceania countries, Afghanistan, Senegal (Kassebaum et al., 2015). Globally, two tendencies in child mortality and illness are highlighted. Yes, mortality dominates for countries with low SDI, and child disability dominates for countries with high economic development. There has been a steady increase in childhood disability in both the United States and Europe (Council of Europe, 2019; European Comparative Data on Europe, 2020).

The data when comparing child mortality rates in India and the United States are impressive (CDC, 2021). For example, among children aged 1-4 years, the number of deaths in India was 1198145, in the United States, 27691; among children 5-14 years, 185,962 and 5,549, respectively (UNICEF, 2021; NCHS, 2021). Each year in Europe, more than 25,000 infants are stillborn, 25,000 newborns do not live to be one year old, 40,000 of those who survive (about 8 out of 1,000 born alive) have sensory or motor impairments, and another 90,000 have severe congenital ones. Thus, the major global tendencies in the system of health and maternal protection are identified. Let us consider in more detail the system of state support for perinatal care in countries.

The experience of Germany can be considered the beginning of active support. Thus, back in the $60 \mathrm{~s}$, the country began to operate special maternity clinics at leading universities, and in the 70 s, they were built into perinatal centers (PC) in connection with the implementation of the state program "Denver". This program provided for the operation of one PC for 10,000 births. According to this program, organizational and educational work was also carried out. It allowed to sharply reduce the mortality rate of children, but another problem emerged - the nursing of deeply premature babies. Budget costs for them were from 100 to 200 thousand marks per child, but these measures were not always successful concerning further health and quality of life of these children (Say et al., 2009; Mahardika et al., 2021). The organizational approach to the formation of PC was implemented by all the countries of Western Europe, and in 2000, such a mechanism was also started in the CIS countries. For example, in 2020, the Kyrgyz-German project "Promotion of perinatal health care in the Kyrgyz Republic" began to be implemented. About 500 people implemented the project to improve the competencies of medical workers, enhance the quality of perinatal care and improve comprehensive care, focusing on the needs of pregnant women and newborns.

For the EU countries in 2014, the European Council and the College of Obstetrics and Gynecology (EBCOG) developed and adopted the "Standards for Women's Health in Europe". These standards were also

Mariya, M., Kuzyk, P., \& Diegtiar, O. (2021). Promoting healthy births and reducing infant mortality through national health system. International Journal of Health Sciences, 5(3), 449-460. https://doi.org/10.53730/ijhs.v5n3.1905 
recommended for Asian and CIS countries. The state implementation of these standards in 28 EU member states has significantly reduced maternal and child illness and mortality rates. However, there remains a high rate of child mortality and disability.

Since 1999 the Euro-Peristat project was launched in Europe as part of the EU state health monitoring program. Currently, 29 countries participate in Euro-Peristat, including all EU member states (except Bulgaria) as well as Iceland, Norway, and Switzerland. The project's Scientific Committee includes one representative from each country, but many countries have formed teams that include perinatal health specialists (Eurostat, 2021). The list of the Euro-Peristat project indicators (Euro-Peristat, 2021) includes 10 core indicators and 20 recommended indicators, grouped into four categories:

- The health of the fetus, a newborn child

- Maternal health

- Characteristics and risk factors

- Health services

We should note that several European states implement the Soviet principles of health care - gratuity and accessibility. That is why their budgetary system of medicine, often called the Beveridge model (it exists, in particular, in Great Britain, Ireland, Denmark, Italy, Spain), has been formed at the event. In addition, most European countries are strengthening budget financing of medicine in general, including perinatal care. This strategy is best embodied in Belarus. Belarus shares first place in the world with Brunei and Canada (according to the report of the World Health Organization (WHO)) on the availability of perinatal medicine.

There is another world indicator used by the WHO: the Millennium Development Goals of reducing child mortality and improving maternal health. The infant mortality rate in Belarus is the lowest in the CIS, and the rate of its reduction is ahead of Belgium, Germany, the Netherlands, France, and Switzerland, countries with a high standard of living. In Belarus, child mortality has been reduced to its lowest level in 10 years, from 4.0 in 1990 to 2.8 in 2020. By the accessibility of health services, Belarus is on a par with such countries as France, Finland, Luxembourg and is among the 50 best countries in the world in terms of pregnancy care and organization of childbirth by qualified medical personnel.

The United Nations Development Program (UNDP) notes that Belarus is among the top twenty countries in ensuring access to clean water. One hundred percent of the population has access to potable water in the country. $92.8 \%$ of the republic's population has access to central water supply, including $83.4 \%$ of agro-city residents. Let us analyze the costs of perinatal care (Table 3). The calculation methodology will be reduced to the deduction of the share of GDP in personal income per capita and the accounting of mortality (per 1000 births). We will get the share of expenses for the struggle for a child's life.

Table 3

Assessment of fighting costs for the lives of newborn infants due to the rate of newborn deaths

\begin{tabular}{|c|c|c|c|c|c|c|}
\hline \multirow{2}{*}{ Country } & GDP & $\begin{array}{l}\text { Healthcare } \\
\text { expenses }\end{array}$ & \multirow{2}{*}{$\begin{array}{l}\text { Average } \\
\text { duration, } \\
\text { years }\end{array}$} & \multirow{2}{*}{$\begin{array}{l}\text { Mortality } \\
\text { per } 1000 \\
\text { liveborn }\end{array}$} & \multirow{2}{*}{$\begin{array}{l}\text { Share of health } \\
\text { care expenses } \\
\text { in GDP per } \\
\text { capita }\end{array}$} & \multirow{2}{*}{$\begin{array}{l}\text { Share of } \\
\text { death } \\
\text { expenses per } \\
1 \text { mortality }\end{array}$} \\
\hline & \multicolumn{2}{|c|}{ per capita, USD } & & & & \\
\hline \multicolumn{7}{|c|}{ Developed countries } \\
\hline USA & 62641 & 9870 & 77 & 5,7 & 15,76 & 2,76 \\
\hline EU & 36532 & 3588 & 79 & 3,5 & 9,82 & 2,81 \\
\hline Japan & 39287 & 4233 & 84 & 1,9 & 10,77 & 5,67 \\
\hline $\begin{array}{l}\text { Republic of } \\
\text { Korea }\end{array}$ & 31363 & 2044 & 82 & 2,8 & 6,52 & 2,33 \\
\hline Canada & 46125 & 4458 & 82 & 4,5 & 9,67 & 2,15 \\
\hline Australia & 57305 & 5002 & 83 & 3,0 & 8,73 & 2,91 \\
\hline \multicolumn{7}{|c|}{ Developing countries of the 1 st tier } \\
\hline P. R. China & 9771 & 398 & 76 & 8,0 & 4,07 & 0,51 \\
\hline Brazil & 8931 & 1016 & 76 & 13,2 & 11,38 & 0,86 \\
\hline
\end{tabular}




\begin{tabular}{|c|c|c|c|c|c|c|}
\hline Russia & 11289 & 469 & 72 & 6,5 & 4,15 & 0,64 \\
\hline Mexico & 9698 & 461 & 77 & 11,5 & 4,75 & 0,41 \\
\hline Turkey & 9311 & 467 & 76 & 10,0 & 5,02 & 0,50 \\
\hline Argentina & 11653 & 955 & 77 & 9,2 & 8,20 & 0,89 \\
\hline Belarus & 6678 & 394 & 69 & 2,8 & 5,90 & 2,11 \\
\hline \multicolumn{7}{|c|}{ Developing countries of the $2 \mathrm{~d}$ tier } \\
\hline India & 2019 & 63 & 68 & 32,0 & 3,12 & 0,10 \\
\hline Indonesia & 3894 & 112 & 69 & 21,4 & 2,88 & 0,13 \\
\hline Philippines & 3103 & 129 & 69 & 22,2 & 4,16 & 0,19 \\
\hline Egypt & 2549 & 131 & 71 & 18,8 & 5,14 & 0,27 \\
\hline Vietnam & 2564 & 123 & 76 & 16,7 & 4,80 & 0,29 \\
\hline Iran & 5415 & 415 & 76 & 12,8 & 7,66 & 0,60 \\
\hline Thailand & 7274 & 222 & 75 & 8,2 & 3,05 & 0,37 \\
\hline RSA & 6340 & 428 & 63 & 28,8 & 6,75 & 0,23 \\
\hline Colombia & 6651 & 340 & 740 & 12,7 & 5,11 & 0,40 \\
\hline Ukraine & 3098 & 141 & 71 & 7,5 & 4,55 & 0,61 \\
\hline Algeria & 4279 & 260 & 76 & 20,6 & 6,08 & 0,29 \\
\hline Iraq & 5878 & 153 & 69 & 25,3 & 2,60 & 0,10 \\
\hline \multicolumn{7}{|c|}{ Economically underdeveloped countries } \\
\hline Nigeria & 2028 & 79 & 53 & 64,6 & 3,90 & 0,06 \\
\hline D. R. of Congo & 2148 & 21 & 59 & 34,7 & 0,98 & 0,03 \\
\hline Pakistan & 1473 & 40 & 66 & 61,2 & 2,72 & 0,04 \\
\hline Bangladesh & 1698 & 34 & 72 & 26,9 & 2,00 & 0,07 \\
\hline Ethiopia & 772 & 28 & 65 & 41 & 3,63 & 0,09 \\
\hline Tanzania & 1051 & 36 & 66 & 38,3 & 3,43 & 0,09 \\
\hline Myanmar & 1326 & 62 & 67 & 38,5 & 4,68 & 0,12 \\
\hline Kenya & 1711 & 66 & 67 & 33,6 & 3,86 & 0,11 \\
\hline Uganda & 643 & 37 & 60 & 35,4 & 5,75 & 0,16 \\
\hline Sudan & 977 & 152 & 64 & 43,7 & 15,56 & 0,36 \\
\hline Afghanistan & 521 & 57 & 64 & 51,1 & 10,94 & 0,21 \\
\hline
\end{tabular}

Source: author's elaboration based on UN Inter-agency Group for Child Mortality Estimation (2021)

This approach in calculating costs indicates that economically developed countries incur the highest costs in the struggle for newborn life, with an average cost of 3.1\%. Among the first-tier developing countries, Belarus has achieved extremely high rates. It has reached the level of developed countries on this indicator. All other countries lag two orders of magnitude behind developed countries in efforts to fight for newborn life. Japan bears the greatest cost of medical struggle in the lives of infants (Lukyanenko et al., 2021). The only country that has survived two nuclear military disruptions and one peaceful one at a nuclear power plant has understood the value of the real cost of medical treatment, including infants, which is why the Japanese have the highest life expectancy at 84 years.

Another confirmation of this approach is the market component of perinatal care. For example, the global market in 2018 was $\$ 3.4$ billion for noninvasive prenatal testing (NIPT). According to forecasts, by 2024, the average annual growth rate of this segment will be $13.5 \%$ and reach 7.3 billion. This growth is due to the increased risk of chromosomal anomalies with increasing maternal age, a shift in focus to noninvasive methods, positive changes in NITT scenarios of public awareness of this diagnostic option. In addition, a significant increase in the number of players in new segments of the noninvasive diagnostics market is expected.

If in 2016 the most developed market for noninvasive prenatal diagnostics was in the United States (the share was more than 50\%), and the second-largest market was in Europe, then for the period of 2022, the second-largest market for NIOSH will be China. The development of the US and European market is conditioned by the increase in state investments and the spreading tendency for the increase in the age of parents (over 35 years) and the increase in the number of chromosomal anomalies. For the Chinese market,

Mariya, M., Kuzyk, P., \& Diegtiar, O. (2021). Promoting healthy births and reducing infant mortality through national health system. International Journal of Health Sciences, 5(3), 449-460. https://doi.org/10.53730/ijhs.v5n3.1905 
the growth factor is driven by improved healthcare infrastructure in the region, rising per capita income, and increased consumer awareness of NIOSH.

The goals of noninvasive prenatal diagnosis are to identify trisomy (it is pertinent to point out that trisomy detection was the largest NIPT market tendency in 2018), microdeletion syndromes, monogenic disorders, or Klinefelter syndrome. NIPT also serves to identify fetal sex or rhesus-factor (Rh). In general, noninvasive prenatal diagnostics market segments, ultrasound; biochemical screening tests; fetal cell-free DNA tests in maternal plasma

Maternal mortality ratios are low in Europe, ranging from less than 3 per 100,000 live births (in Estonia, Italy, Austria, Poland) to 10 per 100,000 live births (in Latvia, Hungary, Slovenia, Slovakia, Romania). It is due to both the low female fertility rate (less than 2 children per woman) and the high level of health care. In addition, scientists prove that statistics on this indicator are understated, so a common mechanism for auditing the accepted standard (Yang et al., 2016). Consequently, confidential investigations and reconciliations with reported cases are conducted to obtain complete data on pregnancy-related deaths of women, as well as to understand the causes of these deaths and to make recommendations to prevent a recurrence. Relevant investigations in France, the Netherlands, and England have indicated that half of maternal deaths are due to inadequate medical care. Research on the regulation of perinatal care in the context of achieving the Sustainable Development Goals focuses on assessing the factors that influence the performance of this care and determining the health of mothers and adolescents.

Numerous research-intensive studies are a basic condition in the development of strategy and tactics of state regulation of perinatal care (Jeremic et al., 2016; Yeo \& Romero, 2017; Sun, 2018). Since 2015 the possibility of using telemedicine and information technology for perinatal care has been actively discussed in international publications (Schwartz et al., 2015). From our point of view, this approach is not determinative in state regulation. Such a policy becomes only an auxiliary tool and in an environment where the professional level of workers, doctors, and patients is high enough. For underdeveloped countries, such medicine is unacceptable.

There is a widespread scientific discussion of the social responsibility of perinatal medicine in the social treatment of disability. Amendments to relevant legislation have been adopted in this perspective (Ville, 2011). However, such an approach is justified only when the system of all medicine works at a high level, and it is exclusively a measure of adjustment of the current medical and social system of the country.

During this period, all medical attention is focused on the fight against coronavirus disease. Therefore, we should expect a series of scientific publications on the effect of coronavirus on fetal abnormalities in women.

Leading researchers (Kikuchi et al., 2016; Kruk et al., 2018), indicate that current tendencies in perinatal care regarding outcomes are characterized by an increasing proportion of increased infant disability. Our study notes that mortality rates are significantly lower in these countries because of the significant costs of preserving life during birth.

Despite the serious study of state regulation of perinatal medicine (Buse \& Hawkes, 2015; Callister \& Corbett, 2017; Boerma et al., 2018), there are no highly specialized studies to evaluate state regulation in the countries that have the lowest global rates of newborn mortality (Japan and Belarus). Therefore, a detailed analysis of the state regulation of perinatal care in these countries is necessary for an implementation to achieve sustainable development in other countries.

\section{Conclusion}

The researchers noted the problem of state regulation of perinatal medical care as urgent and under the close attention of the World Health Organization. Such attention is caused by a rather uncomfortable tendency in mortality rates in the vast majority of countries in the world. At the international level, the perinatal care regulation is implemented in the form of appropriate documentary provisions development and mandatory measures introduced in the medical standards and audits system (Fiscella, 1995). The regulatory and explanatory base of this health area is strong and brought into the mandatory application system of national medicine. Further introduction of appropriate standards and mandatory reporting becomes a prerequisite for international cooperation and international regulation of the medical sphere. 
Diverse projects are underway to monitor the status of these medical problems and assess the level of their solution. There is fruitful cooperation between international organizations and national ministries of health through an extensive system of programs and multifaceted nature. It is clear, however, that at the heart of all maternal, child, and most adolescent health problems is a material and social factor- poverty, inequality (in any form, legal or material), and marginalization. It has formed a critical gap between groups of countries, both in the system of perinatal health care and the actual state of survival of infants and mothers. At the same time, the usual measures of organizational sanitation are influenced by basic education and education.

Also, child mortality and illness ratios are criteria of national health and the main criterion of sustainable development, and directly depend on the standard of living of a particular country in general and the quality of medical care in particular, the characteristics of the nutrition and living conditions of the population, the level of education, culture. The example of Japan, which was able to overcome the problems even of radiation sickness, and Belarus, which was able to achieve a minimum level of infant mortality, show that there can be no impossible medical problems (James, 1993). It is simply necessary for the countries' governments to concentrate on medicine and implement its budget financing, which will subsequently form the conditions and interest of private investors in private investment as well. That is why the WHO general recommendation sounds like the need to apply the system of budget financing on the principles of free and accessible medicine in general and perinatal care in particular.

As for the market approach in perinatal medicine, it works effectively when the country achieves high macroeconomic indicators, which is determined by the pace of economic development of the national economy. Accordingly, such a complete market has been formed in the USA, the EU, and shortly in China. It is a sufficiently capacious and dynamically developing market with great potential of scientific and innovative nature. Undoubtedly, perinatal medicine development allows to effectively overcome the mortality of children and their mothers. That is why there is a steady tendency of falling mortality rates, but at the same time, it indicates a new growing problem in the life of families - increasing disability of infants. This problem remains not even fully understood, and it simply cannot be overcome without a wide range of basic studies. This problem is exacerbated by the tendency of women giving birth to their first child to age.

The current system of statistical reporting of perinatal medicine requires improvement and strict control. Even in economically developed countries, there is falsification and concealment of information. Therefore, the standards' tightening in the medical reporting system becomes a determining condition for international and national not only in the regulation of perinatal medicine. In general, this conducted study reflects the fact that the role of state regulation of perinatal medicine is determinant in the formation of healthy humanity. The results of the scientific article indicate the priority of research on state regulation of perinatal medical care, which should be carried out continuously and in all countries of the world. Particular attention should be paid to countries with low economic and social development. Another area of research on perinatal care should focus on studying the specifics and mechanisms of state regulation of this sphere in Japan and Belarus, which are currently implementing the most effective perinatal care for their citizens. These research' results can be taken into account in training courses and programs on interregional cooperation in perinatal care.

\section{Acknowledgments}

We are grateful to two anonymous reviewers for their valuable comments on the earlier version of this paper.

Mariya, M., Kuzyk, P., \& Diegtiar, O. (2021). Promoting healthy births and reducing infant mortality through national health system. International Journal of Health Sciences, 5(3), 449-460. 


\section{References}

Barnett, K., Mercer, S. W., Norbury, M., Watt, G., Wyke, S., \& Guthrie, B. (2012). Epidemiology of multimorbidity and implications for health care, research, and medical education: a cross-sectional study. The Lancet, 380(9836), 37-43. https://doi.org/10.1016/S0140-6736(12)60240-2

Bhutta Z.A., Das Jai K, Bahl Rajiv, Lawn Joy E, Salam Rehana A, Paul Vinod K, Sankar M Jeeva, Blencowe Hannah, Rizvi Arjumand, Chou Victoria B, Walker Neff. (2014). Can available interventions end preventable deaths in mothers, newborn babies, and stillbirths, and at what cost. The Lancet, 384(9940), 347-370.

Boerma, T., Requejo, J., Victora, C. G., Amouzou, A., George, A., Agyepong, I., ... \& Zaidi, S. (2018). Countdown to 2030: tracking progress towards universal coverage for reproductive, maternal, newborn, and child health. The Lancet, 391(10129), 1538-1548. https://doi.org/10.1016/S0140-6736(18)30104-1

Buse, K., \& Hawkes, S. (2015). Health in the sustainable development goals: ready for a paradigm shift?. Globalization and health, 11(1), 1-8.

Callister, L. C., \& Corbett, C. (2017). Global perinatal nursing research: Sustainable development goals update. The Journal of perinatal \& neonatal nursing, 31(3), 191-194.

Council of Europe (2018). European Union. Youth and Disabilities.

Data Bank (2017). Infant, Child and Teen Mortality. Indicators of Child and Youth Well-Being. Child Trends.

Dye, C., \& Acharya, S. (2017). How can the sustainable development goals improve global health? A call for papers. Bulletin of the World Health Organization, 95(10), 666.

Fiscella, K. (1995). Does prenatal care improve birth outcomes? A critical review. Obstetrics \& Gynecology, 85(3), 468-479. https://doi.org/10.1016/0029-7844(94)00408-6

Hardianti, S., Syarif, S., Ahmad, M., Niswar, M., Stang, S., \& Mastuti, N. L. P. H. (2021). The effect of web-based learning media towards the skills of the second stage of childbirth care practicum in D-III midwifery students. International Journal of Health \& Medical Sciences, 4(2), 226-231.

Hill, K., Thomas, K., AbouZahr, C., Walker, N., Say, L., Inoue, M., ... \& Maternal Mortality Working Group. (2007). Estimates of maternal mortality worldwide between 1990 and 2005: an assessment of available data. The Lancet, 370(9595), 1311-1319. https://doi.org/10.1016/S0140-6736(07)61572-4

James, S. A. (1993). Racial and ethnic differences in infant mortality and low birth weight A psychosocial critique. Annals of epidemiology, 3(2), 130-136. https://doi.org/10.1016/1047-2797(93)90125-N

Jeremic, V., Sénécal, K., Borry, P., Chokoshvili, D., \& Vears, D. F. (2016). Participation of children in medical decision-making: Challenges and potential solutions. Journal of bioethical inquiry, 13(4), 525-534.

Kassebaum, N. J., Smith, A. G., Bernabé, E., Fleming, T. D., Reynolds, A. E., Vos, T., ... \& GBD 2015 Oral Health Collaborators. (2017). Global, regional, and national prevalence, incidence, and disability-adjusted life years for oral conditions for 195 countries, 1990-2015: a systematic analysis for the global burden of diseases, injuries, and risk factors. Journal of dental research, 96(4), 380-387.

Kikuchi, K., Okawa, S., Zamawe, C. O., Shibanuma, A., Nanishi, K., Iwamoto, A., ... \& Jimba, M. (2016). Effectiveness of continuum of care-linking pre-pregnancy care and pregnancy care to improve neonatal and perinatal mortality: a systematic review and meta-analysis. PloS one, 11(10), e0164965.

Kruk, M. E., Gage, A. D., Arsenault, C., Jordan, K., Leslie, H. H., Roder-DeWan, S., ... \& Pate, M. (2018). Highquality health systems in the Sustainable Development Goals era: time for a revolution. The Lancet global health, 6(11), e1196-e1252.

Kyu, H. H., Pinho, C., Wagner, J. A., Brown, J. C., Bertozzi-Villa, A., Charlson, F. J., ... \& Yonemoto, N. (2016). Global and national burden of diseases and injuries among children and adolescents between 1990 and 2013: findings from the global burden of disease 2013 study. JAMA pediatrics, 170(3), 267-287.

Kyu, H. H., Stein, C. E., Pinto, C. B., Rakovac, I., Weber, M. W., Purnat, T. D., ... \& Naghavi, M. (2018). Causes of death among children aged 5-14 years in the WHO European Region: a systematic analysis for the Global Burden of Disease Study 2016. The lancet child \& adolescent health, 2(5), 321-337. https://doi.org/10.1016/S2352-4642(18)30095-6

Lawn, J. E., Blencowe, H., Kinney, M. V., Bianchi, F., \& Graham, W. J. (2016). Evidence to inform the future for maternal and newborn health. Best practice \& research Clinical obstetrics \& gynaecology, 36, 169-183. https://doi.org/10.1016/j.bpobgyn.2016.07.004 
Layuk, N., Wahyuni, S., \& Arifuddin, S. (2021). Differences of heparin binding protein levels in preeclampsian and non preeclampsian women. International Journal of Health Sciences, 5(2), 62-70. https://doi.org/10.29332/ijhs.v5n2.1199

Lukyanenko, N. S., Imanmadiyeva, D. M., Dolinnaya, V. T., \& Spaska, A. (2021). “Clinical masks" of congenital malformations of urinary system in children of early age. International Journal of Health Sciences, 5(3), 244-251. https://doi.org/10.53730/ijhs.v5n3.1458

Mahardika, I. M. R., Suyasa, I. G. P. D., Kamaryati, N. P., \& Wulandari, S. K. (2021). Health literacy is strongest determinant on self-monitoring blood glucose (SMBG) type 2 DM patients during COVID-19 pandemic at public health centre in Tabanan Regency. International Journal of Health \& Medical Sciences, 4(3), 288-297.

Maher, D., \& Cometto, G. (2016). Research on community-based health workers is needed to achieve the sustainable development goals. Bulletin of the World Health Organization, 94(11), 786.

Rasanathan, K., \& Diaz, T. (2016). Research on health equity in the SDG era: the urgent need for greater focus on implementation. International journal for equity in health, 15(1), 1-3.

Requejo, J. H., \& Bhutta, Z. A. (2015). The post-2015 agenda: staying the course in maternal and child survival. Archives of disease in childhood, 100(Suppl 1), S76-S81.

Ruckert, A., Schram, A., Labonté, R., Friel, S., Gleeson, D., \& Thow, A. M. (2017). Policy coherence, health and the sustainable development goals: a health impact assessment of the Trans-Pacific Partnership. Critical Public Health, 27(1), 86-96.

Say, L., Souza, J. P., \& Pattinson, R. C. (2009). Maternal near miss-towards a standard tool for monitoring quality of maternal health care. Best practice \& research Clinical obstetrics \& gynaecology, 23(3), 287-296. https://doi.org/10.1016/j.bpobgyn.2009.01.007

Schwartz, H. P., Bigham, M. T., Schoettker, P. J., Meyer, K., Trautman, M. S., \& Insoft, R. M. (2015). Quality metrics in neonatal and pediatric critical care transport: a national Delphi project. Pediatric Critical Care Medicine, 16(8), 711-717.

Scott, K., Jessani, N., Qiu, M., \& Bennett, S. (2018). Developing more participatory and accountable institutions for health: identifying health system research priorities for the Sustainable Development Goal-era. Health policy and planning, 33(9), 975-987.

Valentine, N. B., \& Bonsel, G. J. (2016). Exploring models for the roles of health systems' responsiveness and social determinants in explaining universal health coverage and health outcomes. Global Health Action, 9(1), 29329.

Ville, I. (2011). Disability policies and perinatal medicine: The difficult conciliation of two fields of intervention on disability. Alter, 5(1), 16-25. https://doi.org/10.1016/j.alter.2010.11.002

Watson, H., Harrop, D., Walton, E., Young, A., \& Soltani, H. (2019). A systematic review of ethnic minority women's experiences of perinatal mental health conditions and services in Europe. PloS one, 14(1), e0210587.

Whipps, M. D., Phipps, J. E., \& Simmons, L. A. (2021). Perinatal health care access, childbirth concerns, and birthing decision-making among pregnant people in California during COVID-19. BMC Pregnancy and Childbirth, 21(1), 1-13.

WHO (2015). The Global Strategy for Women`s, Children`s and Adolescents` Health (2016-2030). Survive, Thrive, Transform. Geneva

Widana, I.K., Sumetri, N.W., Sutapa, I.K., Suryasa, W. (2021). Anthropometric measures for better cardiovascular and musculoskeletal health. Computer Applications in Engineering Education, 29(3), 550561. https://doi.org/10.1002/cae.22202

Wong, Y. S., Allotey, P., \& Reidpath, D. D. (2016). Sustainable development goals, universal health coverage and equity in health systems: the Orang Asli commons approach. Global health, epidemiology and genomics, 1.

Yang, J., Huo, W., Zhang, B., Zheng, T., Li, Y., Pan, X., \& Xu, S. (2016). Maternal urinary cadmium concentrations in relation to preterm birth in the Healthy Baby Cohort Study in China. Environment international, 94, 300306. https://doi.org/10.1016/j.envint.2016.06.003

Yeo, L., \& Romero, R. (2017). Color and power Doppler combined with Fetal Intelligent Navigation Echocardiography (FINE) to evaluate the fetal heart. Ultrasound in Obstetrics \& Gynecology, 50(4), 476-491.

Mariya, M., Kuzyk, P., \& Diegtiar, O. (2021). Promoting healthy births and reducing infant mortality through national health system. International Journal of Health Sciences, 5(3), 449-460. https://doi.org/10.53730/ijhs.v5n3.1905 


\section{Biography of Authors}

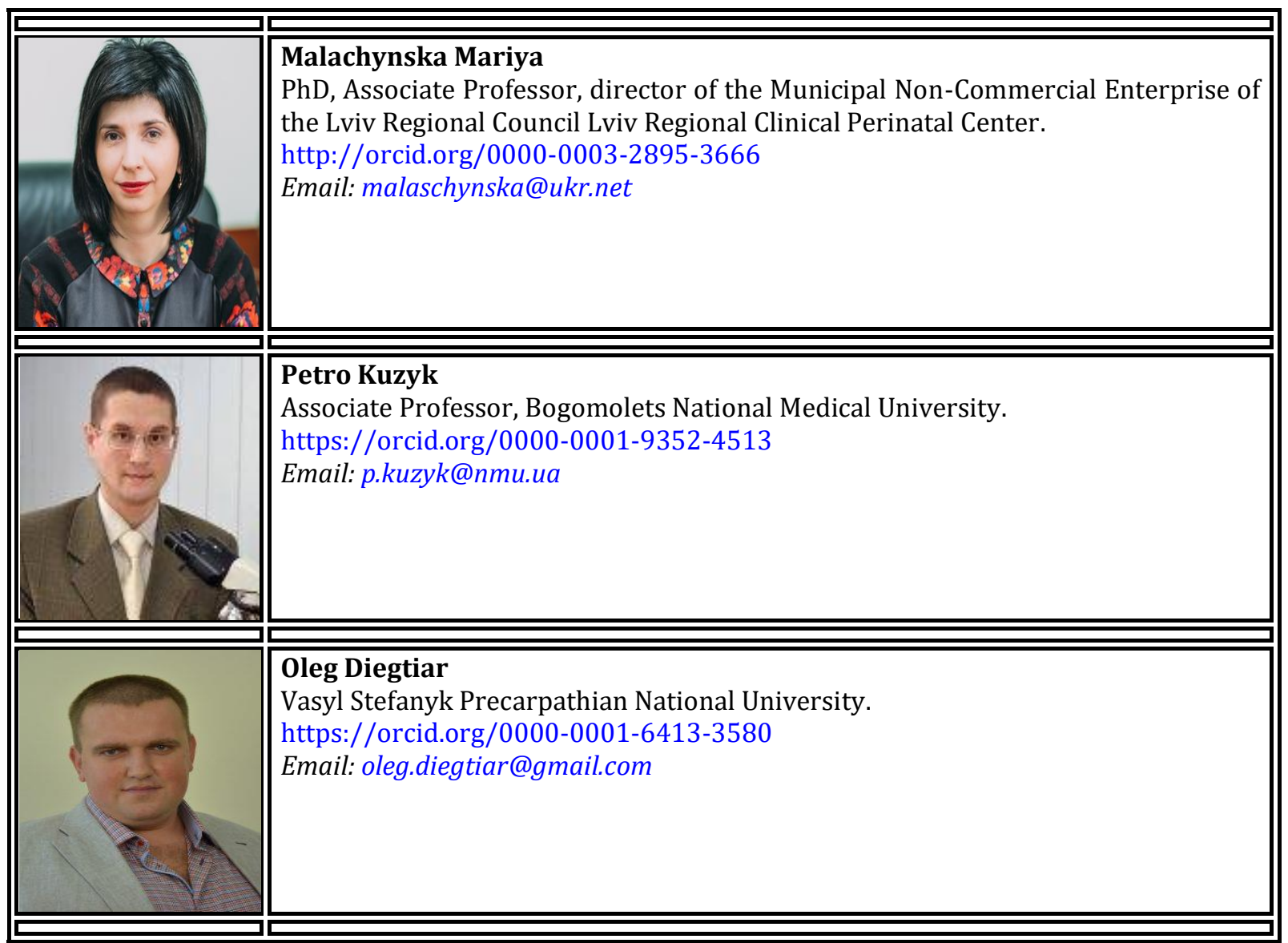

